\title{
COMMENT
}

\section{ECI biocommentary november 2019}

\author{
Adam Numis ${ }^{1}$ \\ Pediatric Research (2019) 86:553; https://doi.org/10.1038/s41390-019-0554-x
}

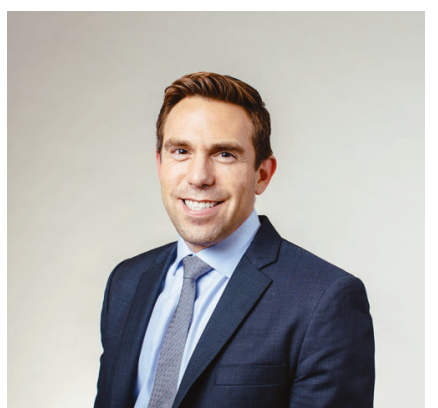

Originally from New York, I went to Harvard Medical School before migrating to the West Coast and completing my clinical training in Pediatric Neurology at UCSF and then Epilepsy at UCLA. My interest in pediatric epilepsy started after a truly life-altering lecture during my second year of Medical School by Dr Elizabeth Thiele. I joined her clinical research group and quickly know I had found my niche! There, I explored the relationship between epilepsy and autism in tuberous sclerosis complex through the examination of clinical, electro-encephalographic, and neuroimaging data. During that time, and in my training, I truly appreciated the anxiety, fear, and uncertainty that afflicts every family with a child struggling with seizures. I had the privilege to witness the spectrum of outcomes in clinical epilepsy - from the joy of developmental gains with improved seizure control to the devastation wrought by "sudden unexpected death in epilepsy,". In seeing the limitations of our current therapeutics, my research interests expanded toward epileptogenesis, and the identification of cohorts for whom therapeutic interventions may prevent future seizure disorders. In an article in this issue, my group demonstrates that elevations in pro-inflammatory molecules in neonates with brain injury are associated with an increased risk of epilepsy. This work laid the groundwork for a K23 grant from the National Institute of Neurological Disorders and Stroke that aims to further explore the association of circulating cytokines and micro-RNA after brain injury and later development of epilepsy. My goal for this work is to better understand whether anti-inflammatory medications could be administered transiently to at-risk braininjured children with the hope of blocking aberrant inflammatory signaling pathways that would otherwise lead to seizures and epilepsy.

As an Assistant Professor of Neurology at UCSF, I continue to surround myself with a group mentors who are excited to pass on their experience and provide ongoing guidance and inspiration. This has led me to forge collaborations with other clinical researchers as well as basic science researchers from disciplines outside of Neurology, to understand novel laboratory techniques. My advice to those starting out in the field is to find that niche that gives you an infectious excitement, so that you can enjoy, and smile every day!

\section{ADDITIONAL INFORMATION}

Competing interests: The author declares no competing interests.

Publisher's note Springer Nature remains neutral with regard to jurisdictional claims in published maps and institutional affiliations.

${ }^{1}$ UCSF-Neurology, San Francisco, CA, USA

Correspondence: Adam Numis (adam.numis@ucsf.edu)

Received: 24 July 2019 Revised: 9 August 2019 Accepted: 16 August 2019

Published online: 2 September 2019 